Biannual Research Journal Grassroots

Vol.55, No.I, 2021: 159-172

Grassroots

\title{
VULNERABILITY OF WOMEN IN DISASTERS: A CASE STUDY OF DISTRICT BADIN
}

\author{
Nosheen Khaskhelly \\ Lecturer, Abida Taherani Sindh Development Studies Centre (SDSC) \\ University of Sindh, Jamshoro \\ Email:nosheen.khaskheli@usindh.edu.pk \\ Dr. Shuhabuddin Mughal \\ Professor Abida Taherani Sindh Development Studies Centre (SDSC) \\ University of Sindh, Jamshoro \\ Email: shahabuddin.mughal@usindh.edu.pk \\ Dr. Erum Khushnood \\ Associate Professor Department of Economics, University of Sindh Jamshoro \\ Email: erum@usindh.edu.pk
}

\begin{abstract}
The climate change is universal phenomenon, its severe impact can be clearly observed in poor countries having mainly dependence on natural resources and having limited coping strategies for extreme climate change. Given the role of women in society, they tend to face more damages in terms of reduction in their income level, saving pattern and the level of education in disaster prone areas. This article examines the impact of disaster on women. The data for study is collected through questionnaire from district Badin of Sindh province. The findings of study revealed that income level of household is affected after disaster, and households who were low at saving pattern are affected more than households with high savings. To combat the impact of disaster on women the government should initiate awareness drive to respond the disaster related vulnerabilities.
\end{abstract}

Keywords: Disaster, Gender, Vulnerability, Poverty

\section{INTRODUCTION}

Women have particularly suffered by the impacts of natural disasters. The prevailing inequalities are the prime source of women's disaster vulnerability. The social changes and variation in global forces is pushing many people to higher risk of disasters and it has disproportionately impacted women. In the context of Pakistan, women are more vulnerable to disaster particularly due to no or less control over ownership of resources. They do not hold any permanent place in decision making and has to suffer traditional, uniform and 
unjustified gender biased domination. Because of inferior position of women economically, socially and politically, she tends to be more vulnerable to disasters.

Pakistan is at epicenter of disaster risks and management from geo-social perspective. The frequent calamities affected Pakistan are earthquakes, floods, droughts, windstorms and landslides causing heavy damages and losses. The weather of Pakistan is mostly dry, even though it is heavily influenced by South East Asian monsoon. Nearly half of rainfall takes place in July and August almost $60 \%$ of area receives less than $250 \mathrm{~mm}$ of rainfall annually, $24 \%$ receives between $250-500 \mathrm{~mm}$. Pakistan is already at risk of heavy floods due to frequent rainfall in North Arabian Sea and experienced severe floods in 1973, 1992, 2006, 2010, 2012, and 2014 (Hyder and Mahmood, 2015).

Women are often not allowed to participate fully in the public sphere, and are therefore less likely to receive critical information enabling appropriate emergency responses. The study found that even though women might receive early warning of approaching storms, women remain dependent on the male household head to take the final decisions on whether the family should retreat to safer places such as cyclone shelters. Women play a complementary rather than independent role in the case of disaster preparedness. However, they do adopt different strategies to men, such as putting aside money, making portable stoves, and maintaining a store of dry foods, molasses, biscuits and essential medicines. For women, running, climbing trees and swimming (even if they are able to) is socially frowned upon. It is observed that women prioritize keeping family members together and taking care of their collective needs as far as possible, whereas men tend to protect themselves first and their assets second. Even though women take on the wider caring responsibilities, they are disadvantaged in access to relief materials because they are not viewed as the main breadwinner of the family.

Human beings perpetuate social patterns of discrimination during and post-disaster period and these established prototypes affect particular group of people to suffer more in comparison to others (Singh, Eghdami and Singh, 2014). As such, the female populace in Pakistan is vulnerable to natural hazards and disasters which are recurrent in country's rural areas. Women in Pakistan are not only 
victims of natural disasters; the same situation is also witnessed in poor communities with low-income of other nations as well. There are variety of factors, including social, economic, cultural, psychological, ethnic and physiological that play vital role and in some cases crucial role in determining the effect of natural disasters on each gender in different ways and degrees.

The women tend to face more damages in terms of loss of life and property during natural disasters due to higher poverty rate among rural women as well as cultural restrictions in our society. The role of women in our society is restricted to ensure food security of households, to achieve this women in rural areas mainly depend on natural resources. In disastrous situation like drought and flooding, the responsibility for women increases and works harder than usual to look for supplemental income for feeding, looking for community shelters, gathering fuel for cooking and caring their family. The women are ignored from health facilities during disasters, specially lactating and pregnant women suffer more (Vasudha, 2008). This paper attempts to analyze the income and saving patterns of women in disaster affected areas of Badin.

\section{LITERATURE REVIEW}

Numerous studies - including this one - provide evidence of the disproportionate burden of climate change and disasters on women. The qualitative information clearly shows, firstly, the already disadvantaged position of women in the study communities, and secondly, the greater suffering and hardship borne by women in the wake of natural disasters.

The individuals in developing countries have limited ability to deal with natural hazards and climatic distress, due to variation in income consumption behavior and variability in weather (Dercon, 2005 and Fafchamps, 2003). The several studies have been conducted to find effects of rapid climate change, whereas there are not sufficient studies on economic impact of natural disaster (Sawada, 2007). Whereas studies with respect economic impact and disaster in view of gender perspective are emerging, this portion of paper reviews some previous relevant studies on vulnerability being faced by women during disasters.

The risk of disaster can be minimized through effective implementation of social protection programs, these programs will 
support in reduction of disaster vulnerability and risk, supporting agricultural growth by introducing awareness for locals to reduce risk in agricultural sector (Farrington et.al., 2007). Due to gender biasness the role of women is excluded, the equal participation in policy intervention programs is found absent, and these programs are formed to support rural community and specifically target the heads of households (Antonopoulos, 2007).

According to Briceno (2002), women are at frontline during catastrophe disaster and pushing them to vulnerable position. It has been argued in several studies that women faced several havocs during disaster that leads to higher death rates specifically in South Asian countries because women tend to stay at home to look after children and valuables (Hena, 1992). Women tend to suffer more during disaster because of their malnourished bodies there capacity to cope with tidal waves during floods miserably fails (Hena, 1992; Chowdhury et.al., 1993). Despite of fighting against such disasters, if a women looses male bread earner in disaster, these needy women are forced to profession of beggary or prostitution for their survival (Rahman, 2013).

Gender discrimination has been witnessed at entire stages of disaster process; risk exposure, risk sensitivity, awareness, material impact, emotional impact recovery and reconstruction (WEF, 2019). This stem less from sexual orientation contrasts per sex, that is, natural and physical difference (in spite of the fact that these can and do put women in danger, e.g., during pregnancies when versatility might be impressively decreased); but instead from sex inequalities. Thus, while men are clearly influenced (and relying upon setting, regularly harder hit by catastrophes) the expansive pattern is that ladies think that it is harsher for them to withstand and react to emergency circumstances (Twigg, 2004).

Salwa (1998) explains a gender is not a merely a difference of physical attributes between women and men, but it is the difference of socially assigned roles and responsibilities in a society. The main cause of increased poverty in our society is due to unbalanced treatment of gender, the society heavily being dominant by man counterpart has social mindset that women should not be allowed to participate in economic activities which is main cause of poverty among women (Muqadissa, 2004). The word gender has been mostly 
misunderstood as the term 'sex' but both words 'gender' and 'sex' are used simultaneously (Marger, 1999).

In times of disaster, women and girls face more risk because of abundant factors primarily due to gender imbalance (Enarson, 2002). Women counterpart face more risk as compared to men due to pregnancy and have no inadequate control over reproductive health; it has been also witnessed that women has longer life span as compared to men and as result their mobility is restricted at old age and are more prone to chronic illness. During disaster situation women face more risk due to variable factors, she experiences more domestic and sexual violence, women are more economically dependent due to lower income as compared to men, have no or limited access to productive resources with limited access to credit. The other reasons for women being more affected in disaster include high illiteracy rate, having no or less control over economic / social decision-making.

Simultaneously, these factors offer rise to various crosscutting vulnerabilities, including social weakness because of absence of incorporation in basic leadership; physical powerlessness because of restricted access to and authority over monetary and physical assets, for example, cash, lodging, land, and different resources; and mental defenselessness brought about by view of having next to zero command over one's life.

The socioeconomic consequences faced by surviving women are very disturbing, it was seen that to mitigate the economic suffering, poor women were often forced to sell their only asset such as jewellery. The women also go through hardship for protecting their family from health hazards, arranging medicine and meals often covering several miles to obtain water for cooking and washing purpose (Nasreen and Hossain 2002).

\section{IMPACT OF NATURAL DISASTERS ON WOMEN}

Extremely vulnerable women have particular interests and needs before, during and post disaster. The levels of vulnerability vary with specific gender shapes. Women are considered as energetic and active responder of disastrous situation but often considered as helpless victims. There are multiple causes which are mainly accountable for vulnerability of social structure and people as far as natural disaster occurrence is concerned. 
Biannual Research Journal Grassroots Vol.55, No.I: 159-172

TABLE-1

PRIMARY CAUSES INFLUENCING THE VULNERABILITY OF PEOPLE AND SOCIAL STRUCTURES

\begin{tabular}{|c|c|}
\hline Vulnerability & Causes \\
\hline $\begin{array}{l}\text { Material / economic } \\
\text { vulnerability }\end{array}$ & Lack of Access to resources \\
\hline Social Vulnerability & Disintegration of social Patterns \\
\hline Ecological Vulnerability & $\begin{array}{l}\text { Degradation of the environment and } \\
\text { inability to protect it }\end{array}$ \\
\hline Organizational Vulnerability & $\begin{array}{l}\text { Lack of strong national and local } \\
\text { institutional structures }\end{array}$ \\
\hline Educational Vulnerability & $\begin{array}{l}\text { Lack of access to information and } \\
\text { Knowledge. }\end{array}$ \\
\hline $\begin{array}{l}\text { Attitudinal and motivational } \\
\text { vulnerability }\end{array}$ & Lack of public awareness \\
\hline Political vulnerability & $\begin{array}{l}\text { Limited access to political power and } \\
\text { representation }\end{array}$ \\
\hline Cultural vulnerability & Certain beliefs and customs \\
\hline Physical vulnerability & Weak buildings or weak individuals. \\
\hline
\end{tabular}

The primary reason of increase in women vulnerability is due to biological reasons; the other social and cultural factors are associated deeply with community. The women have to undergo various situations at different stages of disaster. In post-disaster women were bartered for food when sufficient relief did not reach. In late post disaster period, the girls were married at younger age or wedded to older persons. Women are deprived from basic health needs; pregnant women do not have obstetrical care and chances of miscarriage increase and deliveries are done under very unhygienic conditions. Women are left without relief during disasters; they even may not receive blankets, mattresses and even necessary food items for survival.

\section{ECONOMIC VULNERABILITY FACED BY WOMEN DURING DISASTER}

The economic vulnerability for women increase due to disaster as women is expected to perform traditionally assigned duties like childcare, nursing the injured and providing financial support to those who have lost their partners or parents. 
The prevailing gender inequalities have created distinguished impact of disaster on men and women. The study conducted in 2007 by London School of Economics to witness the natural disaster impact over the period 1981 to 2002, in which sample of 141 countries was taken. It was found that on average more women were killed than men or women at earlier age were killed more than men due to lower socioeconomic status of women (Neumayer and Plumper, 2007).

In rural areas women are engaged working in informal economy or agriculture sector, both of them are badly impacted by natural disasters. Due to low literacy rate among rural women their representation is not properly done and ends up with unemployment. Women in rural areas even cannot relocate in search of better job due to their caretaking responsibilities; as a result, they are at risk of impoverishment, forced marriage, trafficking and labor exploitation. The pace of recovery at time of disaster depends upon economic status of women. Poor families headed by female household head have almost no resources to rebuild their lives.

\section{ROLE OF WOMEN IN DISASTER PREPAREDNESS}

Women are likely not to receive early critical information regarding disasters, enabling them to react with delayed suitable emergency response. They are also restricted not to participate in disaster related community gatherings. It is also an annoying fact in our society that due to dominance of male household, even if women receives early warning regarding floods or storms through community volunteers, radio and by neighbors word of mouth, they remain dependant on decision of man head household of family that either move the family at some safer place or not. It was also evident in some cases the women played complementary role despite of independent role in disaster preparedness; they adopt different strategies from men such as saving money for difficult situations, making portable stoves and reserving dry foods and basic medicines to combat the critical situation.

It is endorsed worldwide that people's vulnerability to disaster risk mainly relies on available assets. In general women have no or limited access to assets such as physical, financial, land and capital. The special focus is required to enhance women's capacity to handle disaster risk by reducing vulnerability and increasing opportunity for development (Aguilar, Anderson-Nathe \& Abrahms, 2008). 


\section{CHALLENGES DURING DISASTER}

It is socially frowned upon for women, climbing trees, running, and swimming (even they are able to) and movements are restricted due to traditional dress of women, confining their ability to reach at safer place during emergency situations. The shelters in disaster prone areas lack adequate facilities for women, such as, there is rarely any separate washroom facility for women. The availability of inadequate healthcare for women leads to wards reproductive and health problems. The ratio of harassment is also on higher side of pregnant women and teenager girls in shelters, specifically when they are separated from family member.

\section{THEORETICAL BACKGROUND}

This research is based on rural area affected by frequent disaster in Badin District of Sindh Province. The strong gender based norms and feeble support system during time of disaster was witnessed. Due to all these reflected features in Figure-1, the impact of disaster on women is likely to be severe. 


\section{FIGURE-1 \\ OVERALL RURAL ENVIRONMENT}

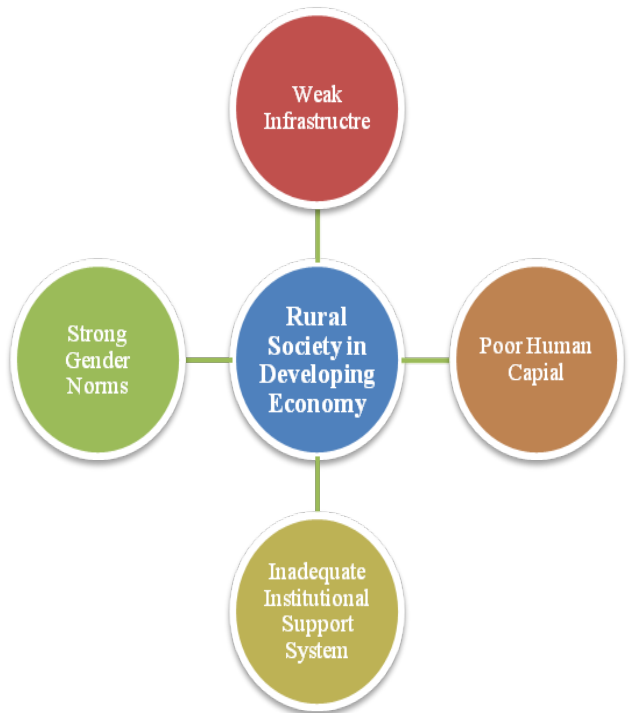

In Figure-1, the overall rural environment is presented along with its characteristics like weak infrastructure, strong gender norms, poor human capital and inadequate institutional support system.

\section{RESEARCH METHODOLOGY}

The research study is based on quantitative data and field visits to flood affected areas in district Badin of Sindh Pakistan. The data was gathered mainly from 08 underdeveloped villages in district Badin.

The sample size of study area consists of 160 respondents out of which $42 \%$ were male and $58 \%$ were female. The literacy rate of women in study area is: $76.3 \%$ were illiterate, $15.1 \%$ primary, $4.3 \%$ secondary, $3.2 \%$ intermediate and only $1 \%$ graduate. The household size is alarming and extended family structure was seen with average household size of nearly 7.6. Most of the people i.e. 67\%were living in katcha houses (made of mud and wood), 14\% lives in pacca house (made of bricks cement and iron) and 19\% lives in semi pacca houses (made of brick and mud with partial cement). 


\section{FINDINGS}

To examine the disaster vulnerability of women in study area, we have used the income as variable to determine the impact, saving behavior before and after disaster and its relationship with education status of women.

TABLE-2

AVERAGE INCOME OF RESPONDENTS BEFORE AND AFTER DISASTER (IN PKR)

\begin{tabular}{|cccc|}
\hline Gender & $\begin{array}{c}\text { Before } \\
\text { Disaster }\end{array}$ & $\begin{array}{c}\text { After } \\
\text { Disaster }\end{array}$ & Impact \\
\hline Male & 6,441 & 5,478 & $15 \%$ \\
\hline Female & 4,307 & 3,436 & $20 \%$ \\
\hline
\end{tabular}

Source: Study Survey 2014-15.

FIGURE-2

$\square$ Male $\square$ Female

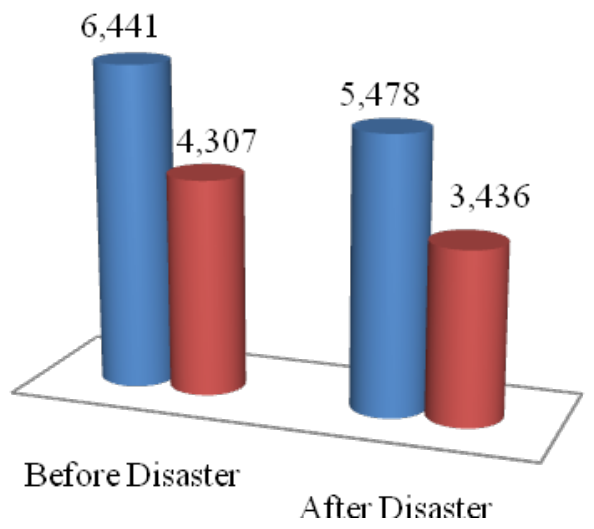

Table-2 reflects the income of respondents; before and after disaster to find out the impact on earning of respondents due to disaster. District Badin being the poorest district in Sindh province has average male monthly income before disaster is Rs.6,441/= and for female for same period it is Rs.4,307/= which is nearly $19.85 \%$ less as compare to income of male. The results reflect that earning opportunities for women in rural areas are really less or they are exploited and paid less. Most of the females in rural areas are skilled in 
handicrafts and spent their majority of time in this profession to support their family but due to limited access to market they sell their handmade thing at very low prices to local brokers and pay less. The earning situation even get worst for people after disaster; there earnings are badly affected and there average monthly income reduces. It was witnessed that in study area the monthly income of women is affected more as compared to male. There is reduction of $20 \%$ monthly income of women after disaster as compared to $15 \%$ of male. The results clearly portray that disaster have more economic impact on female than male.

TABLE-3

SAVING PATTERN OF RESPONDENTS BEFORE AND AFTER DISASTER

\begin{tabular}{|l|l|l|}
\hline Gender & Before Disaster & After Disaster \\
\hline Female & $29 \%$ & $39 \%$ \\
\hline Male & $37 \%$ & $46 \%$ \\
\hline
\end{tabular}

Source: Study Survey 2014-15.

FIGURE-3

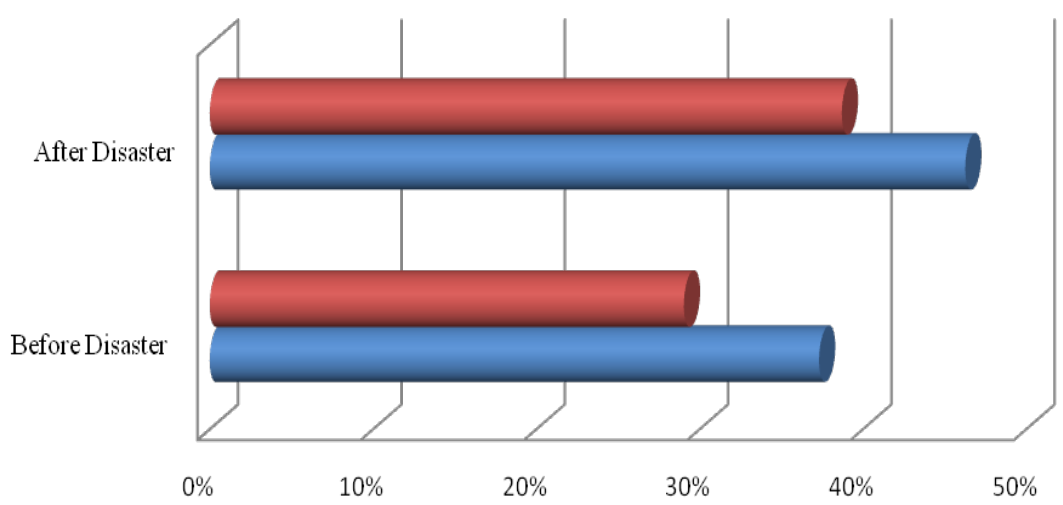

The Saving pattern among the respondents has been analyzed in Table-3. The savings play a very important role in reduction of vulnerability. The pattern of saving was witnessed in disaster hit areas of district Badin of Sindh Pakistan, but results are really not encouraging as we observed that saving habit was more in male as compared to women. There were nearly $37 \%$ male respondents in study area before disaster who have saving habit contrary the ratio of female was less and reported to be $29 \%$. But saving pattern was seen on rising trend after disaster and there was increase of $10 \%$ saving in 
female respondents where as only $9 \%$ rise was seen from male $45 \%$. It is worth to mention here that a penny saved for rainy days will lead you to less vulnerability. The women saving pattern is less due to couple of reasons they are; economic dependency of female on male counterpart, limited or no access to resources and it was also seen that females were under paid as well, leaving women at vulnerable position during disaster.

The literacy rate is also key variable to cope with vulnerability during disasters; it is observed that female literacy rate is in fact poor in rural areas of Sindh Province. In study area there were nearly 76.3\% women were illiterate, such a rising number determines that majority of female are dependant. These illiterate females were also betrayed from participating in community gatherings regarding disaster preventions, so have less or no knowledge to tackle with situation leaving them at vulnerable position.

\section{CONCLUSION}

Disasters have affected men and women, young and old, the poor and rich in multiple ways. International humanitarian organizations are emphasizing on development of strategies which can respond to vulnerabilities arising from disaster and lessen the impact of disaster. But still there is much to be done. The study found that women contributed in almost every sphere of life along with men and even performing some tasks independently.

Despite facing a number of very large-scale natural disasters in recent years, and despite recognition of the need for a coordinated disaster management system focused on risk reduction and preparedness as well as disaster response, Pakistan's ability to effectively manage disasters remains weak. The existing disaster management framework in Pakistan includes gender to a very limited extent. Against this backdrop, it is not surprising that the specific and pressing needs of women in disaster situations have been neglected. At the legislative and policy level, the Government of Pakistan continues to have legal and stated commitment to mainstreaming gender in its climate and environment related policies. In reality though there is very little understanding or internalization of gender issues, it is always tacked on almost as an afterthought and then too as something to do with women alone in every policy document, but there is little 
understanding and perhaps even sympathy towards how to mainstream it.

The voice of women is not heard in rural household and never has been part of any disaster prevention measures. As a result, due to lack of involvement of women in household matters, the disaster prevention strategies are not effectively implemented. Based on the findings, this study suggests that government should make strategies for disaster prone areas; that evacuation from affected area should be done timely along with their valuable belongings. The disaster warning mechanism among villagers should be developed in areas where there is recurrence of natural disasters. Finally the women participation should be increased in community gathering regarding disaster prevention and coping strategies, so that disaster related vulnerability of women should be reduced to some extent.

\section{REFERENCES}

Anguilar, J., Anderson-Nathe, B. \& Abrahms, L.S. (2008). Gender Discrimination in sub-urban settlements', Men and Masculinities, 11(1):22-41.

Antonopoulos, R. (2007). The Right to a Job, The Right Types of Projects: Employment Guarantees Policies From a Gender Perspective. Working Paper No. 516, New York: The Levy Economics Institute of Bard College.

Briceno, S. (2002). Gender mainstreaming in disaster reduction. New York: International Strategy for disaster reduction.

Dercon, S. (2005). Insurance Against Poverty. Oxford: Oxford University Press.

Enarson, E. (2002). Environmental Management and Mitigation of Natural Disasters: A Gender Perspective. New York: United Nations, Commission on the Status of Women, 46th Session.

Fafchamps, M. (2003). Rural Poverty, Risk and Development Cheltenham, UK: Edward Elgar.

Farrington, J., Holmes, R. and R. Slater. (2007). Linking social protection and the productive sectors. Briefing Paper 28, London: Overseas Development Institute.

Hena, H. (1992). 'Why Women Appear Vulnerable', In Hossain H, Dodge C.D., Abed, F.H. (Eds.). From Crisis to Development: Coping with Disasters in Bangladesh. Dhaka: University Press Limited, pp.67-73.

Hyder, A. and Mahmood, Z. (2015). Women at Frontline during the Flood Catastrophe: A Case Study from Pakistan. Pakistan Journal of Women's Studies Alam-e-Niswan, Vol.22, No.2:23-41, ISSN: 1024-1256.

Muqadissa, M.H. (2004), "Gender aspects and issues in Pakistan". Proceedings of the International Conference on Social Sciences: Endangered and Engendered, Fatima Jinnah Women University. 
Nasreen, M. and Hossain, M. (2002). Environment and Sustainable Development: Bangladesh Perspective. Bangladesh Environment 2:11221136.

Neumayer, E. \& Plumper, T. (2007). The gendered nature of natural disasters: The impact of catastrophic events on the gender gap in life expectancy 1981-2002, LSE Research online, Annals of the Association of American Geographers, 97(3):551-566.

Rahman, Habibur and Alam, K. (2016). The impact of natural disasters on women: A case study from Bangladesh.

Rahman, M.S. (2013). Climate Change, Disaster and Gender Vulnerability: A Study on Two Divisions of Bangladesh, American Journal of Human Ecology Vol.2, No.2:72-82 DOI: 10.11634/216796221302315

Salwa, I. (1998). Confronting the other: identity, culture, politics, and conservative Islamism in Egypt. International Journal of Middle East Studies, Vol.30, No.2, Cambridge: Cambridge University Press, 1998, (pp.214-221).

Sawada, Y. (2007). The impact of natural and manmade disasters on household welfare. Agricultural Economics, 37 (Supplement), pp.59-73.

Sindh, S.R., Eghdami, M.R. and Sindh, S. (2014). The Concept of Social Vulnerability: A Review from Disasters Perspectives, International Journal of Interdisciplinary and Multidisciplinary Studies (IJIMS), Vol.1, No.6:71-82. Retrieved from: http://www.ijims.com

Twigg, J. (2004). 'Disaster Risk Reduction: Mitigation and Preparedness in Development and Emergency Programming.' In Good Practice Review, London: Overseas Development Institute Humanitarian Practice Network.

Vasudha, G. (2008). Role of Women in Disaster Management: An Analytical Study with Reference to Indian Society. The 14th World Conference on Earthquake Engineering October 12-17, Beijing, China.

World Economic Forum. (2019). Global Gender Gap Report, Geneva. 